\title{
Relationship Between Cognitive Function, Vascular Age and Stress
}

\author{
Kazue Sawami*, Himeyo Nakagawa and Tetsuro Kitamura \\ Department of Medical Science Nursing, Nara Medical University, Japan
}

Submission: March 29, 2017; Published: October 16, 2017

*Corresponding author: Kazue Sawami, Department of Medical Science Nursing, Nara Medical University, Japan, Email: sawami@naramed-u.ac.jp

\begin{abstract}
Introduction: Alzheimer's type dementia (AD) accounts for at least $60 \%$ of total dementia cases. Furthermore, in people over the age of 65 the incidence rate doubles, which highlights the urgent need to develop preventative measures or delay disease onset. Therefore, we carried out a study involving interventions that combined group-games and brain training among the elderly in the Kashihara-City. Additionally, in order to determine the relation between body composition and cognitive function, we carried out the measurements with an inner scan monitor. Further, to quantify the relationship between stress and cognitive function, the degree of stress was measured using salivary gland amylase levels. The purpose of this study was to examine the effect of interventions in combinations of group-games and brain training on cognitive function, and determine the correlation between cognitive function and body composition, as well as to examine the correlation between and stress levels on cognitive function.
\end{abstract}

Methods: A screening test for mild cognitive impairment: Montreal Cognitive Assessment (MoCA test), measurement of body composition by an inner scan monitor, and stress level tests were performed by measuring $\alpha$-amylase levels in the saliva from the sub lingual gland. For statistical evaluation of scores before and after each cognitive test intervention, tests were used. To test for relationships between the score of cognitive test and measured value of body composition and $\alpha$-amylase levels, Pearson 's correlation coefficient was used.

Results: Significant improvements in cognitive function were detected after each intervention, with the strongest correlating variable with the cognitive function and body composition comparisons being blood vessel age. Furthermore, there was a negative correlation between stress and cognitive function, with those patients with high stress levels having a reduced cognitive function.

Conclusions: Interventions that combine group-games and brain training are effective in preventing dementia. Negative correlations were detected between cognitive function and vascular age, and stress levels. Therefore, in order to maintain the cognitive function, it is necessary to improve the dietary life as a means of improving vascular age and perform activities to provide stress relief.

Keywords: Cognitive function; Vascular age; Stress; Group-games; Brain training

\section{Introduction}

Elderly people over the age of 65 years have a higher incidence of developing dementia [1], with the rate doubling every 5 additional years of ageing [2]. Therefore, the establishment of preventative measure is urgently needed. Unfortunately, amyloid vaccines developed in 2000 were not able to suppress the decline in cognitive function despite reductions in amyloid- $\beta$ levels in the brain of treated patients [3]. Since preventive measures before onset is most likely to be effective, a worldwide Alzheimer's Disease Neuroimaging Initiative (ADNI) has been established to create a standardized test index that can detect AD before onset of disease and also to track its progress [4]. The Japanese division, J-ADNI, was established in 2007, but regional centers are still being sought.
These trends in disease management motivated us to begin testing interventions that combine group-games and brain training for elderly people in Kashihara-City. The reason for using group-games is that interpersonal brain games are more effective for preventing dementia than personal brain training [5]. We hypothesized that combining brain training with groupgames, which is considered to be highly effective, would further enhance this effect. In brain training, n-back task (memory retention task answering Nth previous tasks) is proven to be effective, and has been verified to activate the frontal lobe and parietal cortex region [6]. In addition, it is reported that the brain becomes more activated with dual-tasks (concurrent performance of two tasks) as compared with a single task 
(performance of a single task, such as exercise or learning alone), which increased activation of the prefrontal cortex $[7,8]$. With these research findings in mind, the present study was designed with interventions with combinations of group-games, the n-back task, and dual-task.

Additional factors strongly associated with AD either alone or in combination are common diseases or lifestyle choices such as hypertension, obesity, smoking, dyslipidemia, diabetes and diet. The risk for AD increases in individuals with several predispositions: about 2 times for hypertension, 2.1 times for obesity (BMI 30 or more), 1.8 times for smoking, 2.9 times for dyslipidemia (total cholesterol level $250 \mathrm{mg} / \mathrm{dl}$ or more), and 4.6 times for diabetes (HbA1c 7\% Or more) [9]. Also, since the brains of AD patients display increased oxidation modification products [10], therefore, an improvement of dietary habits could be an important method of prevention. In this study, we focused on the fact that there is a relationship between $\mathrm{AD}$ and body composition, which is the result of a poor long-term dietary lifestyle. In order to further validate the relationship between the body composition and cognitive function, we carried out measurements with the inner scan monitor and compared these to cognitive function. Non-pharmacological therapeutic approaches for maintaining cognitive function such as, promoting relaxation with music therapy and horticulture therapy, are known to activate the intracerebral reward system area, and the patients are likely to continue to practice these types of therapies. Furthermore, in a study comparing the influence of positive and negative emotions with reference to the neutral state, positive emotions widen the range of attention, thinking, and action, whereas reductions in the range of these factors have been reported to be associated with negative emotions [11]. In addition, there are reports that show improvement of selfconfidence influences memory improvement [12]. Therefore, interventions that are able to improve positive emotions in a state of comfort are necessary. Nonetheless, there are only few studies that have investigated the extent to which cognitive function correlates with stress. Therefore, we strived to further validate the relationship between stress and cognitive function, and also to determine whether there is a change in stress before and after the intervention. Stress was measured by salivary gland $\alpha$-amylase collection. Salivary gland $\alpha$-amylase is known to increase with unpleasant stimulation and conversely decreases with the state of comfort $[13,14]$.

The purpose of this research is to verify the effect on cognitive function by intervention of group-games combined with brain training, to clarify the relationship between cognitive function and body composition, and to clarify the relationship between cognitive function and stress.

\section{Methods}

a. Target cohort: 281 elderly people who applied for group-games brain training advertised by public relations. b. Control group: 116 people; mean age $75 \pm 6.3$ years old; 11 males, 105 females.

c. Intervention group: A total of 165 persons; mean age $74 \pm 7.5$ years old; 17 males and 148 females.

d. Study period: August 2015 - February 2016.

\section{Evaluation and analysis}

Measurement of cognitive function: Japanese version of the Montreal Cognitive Assessment (MoCA-test): This is a cognitive screening instrument developed to detect mild cognitive impairment (MCI). It assesses different cognitive domains: attention and concentration, executive functions, memory, language, visuoconstructional skills, conceptual thinking, calculations, and orientation. The time taken to administer the MoCA-J is approximately 10 minutes. The total possible score is 30 points; a score of 26 or above is considered normal.

Body composition monitors: Inner scan monitor: The monitors use bioelectric impedance analysis (BIA) to monitor multiple components of overall health. Measurements include weight, body mass index (BMI), body fat, basal metabolic rate (BMR), metabolic age, bone mass, muscle mass, physique rating, and visceral fat rating.

Vascular age measurement system: Measurement is performed by placing the finger on the sensor. Blood vessel age was measured by assessing the amount of blood flow between the first joint from the tip of the finger.

Table 1: The reference values of salivary $\alpha$ - amylase.

\begin{tabular}{|c|c|}
\hline $0-30 \mathrm{KU} / \mathrm{L}$ & There is no negative stress. \\
\hline $31-45 \mathrm{KU} / \mathrm{L}$ & There is slight negative stress. \\
\hline $46-60 \mathrm{KU} / \mathrm{L}$ & There is negative stress. \\
\hline $61 \mathrm{KU} / \mathrm{L}$ 以 & There is a high amount of negative stress. \\
\hline
\end{tabular}

Measurement of positive and negative mood: The Positive and negative mood was measured by collecting sublingual saliva and measuring salivary $\alpha$-amylase concentration (NIPRO; catalog number, 34549000). This was measured before intervention. Salivary $\alpha$ - amylase reflects sympathetic nervous activity. It rises following a negative stimulus, and reduces following a positive one 17 . The reference values of salivary $\alpha$ - amylase by NIPRO, the manufacturer of the measurement device, is as follows: Table 1.

\section{Analytical methods}

To compare MoCA scores before and after the intervention, paired t-test were conducted. Correlations of MoCA scores with body composition and salivary $\alpha$-amylase were computed using Pearson product-moment correlation coefficients.

\section{Ethical considerations}

The outline of the research, voluntary nature of participation, anonymity, and agreement regarding the publication of the 


\section{Current Research in Diabetes \& Obesity Journal}

document were explained to prospective participants, both in writing and verbally, and their consent was subsequently obtained. The study protocol was approved by the ethical review board of Nara Medical University.

\section{Results}

Of the 281 registrants, 271 people (96.4\%) completed the study and were analyzed.

a. Control group: A total of 112 people, mean age $75 \pm 6.3$ years old, nine men and 103 women. b. Intervention group: A total of 159 people, mean age $74 \pm 7.5$ years old, 15 males and 144 females.

As shown in the Table 2, in the intervention group, the total average score of MoCA-test taken before the intervention was 24.39 ( $<26$ points), and it did not reach significance. The total score value of, 24.05, pre-intervention failed to reach significance, but increased to 26.11 after intervention, which was a statistically significant value $(\mathrm{p}<0.01)$. The results taken at the same time points showed little differences in the control group scores, both of which were below the cutoff value $(<26$ points).

Table 2: Comparison before and after the intervention and control groups.

\begin{tabular}{|c|c|c|c|c|c|}
\hline \multirow[t]{2}{*}{$\begin{array}{l}\text { MoCA Test } \\
\text { Component }\end{array}$} & \multirow[t]{2}{*}{ Description of the Test Component (Maximum Score) } & \multicolumn{2}{|c|}{$\begin{array}{l}\text { Mean Score of } \\
\text { Control Group }\end{array}$} & \multicolumn{2}{|c|}{$\begin{array}{c}\text { Mean Score of } \\
\text { Intervention } \\
\text { Group }\end{array}$} \\
\hline & & Before & After & Before & After \\
\hline Trail Making & $\begin{array}{c}\text { Subject alternates between connecting numbers and connecting letters, in } \\
\text { the ascending order" } 1 \rightarrow A \rightarrow 2 \rightarrow B \text {..." [1] }\end{array}$ & 0.72 & 0.73 & 0.77 & $0.87^{*}$ \\
\hline $\begin{array}{l}\text { Visuoconstructional } \\
\text { skills }\end{array}$ & The participant is asked to accurately replicate a drawing of a cube [1]. & 0.67 & 0.68 & 0.72 & 0.79 \\
\hline Verbal fluency & $\begin{array}{l}\text { The participant is asked to list as many words as possible that begin with a } \\
\text { designated letter of alphabet [1] }\end{array}$ & 0.31 & 0.42 & 0.40 & 0.46 \\
\hline Repetition & The participant is read a sentence and asked to repeat it back exactly [2]. & 0.77 & 0.76 & 0.81 & $0.98^{* *}$ \\
\hline Abstract thinking & $\begin{array}{l}\text { The participant is required to describe what characteristic } 2 \text { words have in } \\
\text { common [2] }\end{array}$ & 1.63 & 1.68 & 1.67 & 1.74 \\
\hline Naming & $\begin{array}{l}\text { The participant is shown pictures of animals and asked to correctly name } \\
\text { them [3] }\end{array}$ & 2.80 & 2.84 & 2.88 & 2.92 \\
\hline $\begin{array}{l}\text { Visuoconstructional } \\
\text { skills }\end{array}$ & The partipcant is asked to draw a clock in a specified period of time [3]. & 2.32 & 2.46 & 2.50 & $2.69 *$ \\
\hline $\begin{array}{l}\text { Short-term memory } \\
\text { recall }\end{array}$ & The participant must recall a list of 5 words [5] & 3.09 & 3.95 & 3.36 & $4.34^{* *}$ \\
\hline $\begin{array}{l}\text { Attention, } \\
\text { concentration, other }\end{array}$ & Repeat, reciprocal number, target detection, subtraction task [6]. & 5.39 & 5.37 & 5.38 & $5.66^{* *}$ \\
\hline Orientation & $\begin{array}{c}\text { The participant is asked to give precisely the current date as well as their } \\
\text { present location [6]. }\end{array}$ & 5.32 & 5.39 & 5.56 & 5.65 \\
\hline Total score & $\begin{array}{c}\text { The total possible score is } 30 \text { points. A score of } 26 \text { or above is considered } \\
\text { normal. }\end{array}$ & 23.02 & 24.27 & 24.05 & $26.11^{* *}$ \\
\hline Salivary $\alpha$-amylase & $\begin{array}{c}\text { Salivary } \alpha \text { - amylase reflects sympathetic nervous activity. It rises following a } \\
\text { negative stimulus, and reduces following a positive one }\end{array}$ & 45.64 & 46.90 & 46.89 & $35.06^{* *}$ \\
\hline
\end{tabular}

Corresponding paired t-test, $\mathrm{n}=271$ (intervention group, $\mathrm{n}=157$; control group, $\mathrm{n}=112$ ).

* Significant at $5 \%$ level.

** Significant at $1 \%$ level.

Each of the following measures of cognitive function; trail making/ Visuoconstructional skills, Repetition, short-term memory recall, attention, concentration, other (attention, memory ability), were significantly improved $(\mathrm{P}<0.05)$. Regarding the degree of stress, measurements of salivary $\alpha$-amylase showed virtually no change between measurements. In contrast, the levels of $\alpha$-amylase in the intervention group demonstrated a significant reduction from $46.89 \mathrm{KU} / \mathrm{L}$ preintervention to $35.06 \mathrm{KU} / \mathrm{L}(\mathrm{p}<0.01)$ post-intervention.

Next, as shown in total score of MoCA-test and stress; $\alpha$-amylase levels, there is a negative correlation between cognitive function and stress, , and those with a high cognitive

function had low stress levels (Pearson correlation coefficient $r=-0.49$ ).

Next, the results of Body Composition and Vascular Age are shown: Table 3. As shown in the table, Body Composition decreased with age, but visceral fat was increased in the age 70 's group compared to the age 60's group. Vascular age was also slightly higher in individuals in the age 70's group than in the age 80's group. As shown the strongest correlation was found between cognitive function and vascular age ( $p<0.01)$. In addition, cognitive function correlated with basal metabolism, bone mass, and muscle mass ( $\mathrm{p}<0.05)$. 


\section{Current Research in Diabetes \& Obesity Journal}

Table 3: Average values of body composition and vascular age.

\begin{tabular}{|c|c|c|c|c|c|c|c|c|}
\hline Ages & Body Mass Index & Body Fat & Muscle Mass & Bone Mass & $\begin{array}{c}\text { Visceral Fat } \\
\text { Rating }\end{array}$ & $\begin{array}{c}\text { Basal } \\
\text { Metabolism }\end{array}$ & Metabolic Age & Vascular Age \\
\hline $60 \mathrm{~s}$ & 23.96 & 32.37 & 36.34 & 2.19 & 7.27 & 1119.9 & 58.85 & 63.07 \\
\hline $70 \mathrm{~s}$ & 23.46 & 30.73 & 35.66 & 2.09 & 8.08 & 1079.3 & 65.17 & 68.96 \\
\hline $80 s$ & 21.13 & 27.70 & 30.67 & 1.67 & 6.33 & 913.6 & 69.33 & 67.50 \\
\hline
\end{tabular}

\section{Discussion}

Preventive intervention for AD in each municipality is still in an experimental state, highlighting the need to establish and implement more effective techniques. In this study, we show that our strategy demonstrated to have significant functional improvements in measures of cognitive function efforts, such as Trail Making. Visuoconstructional skills (Reproductive ability of the viewing space), Repetition (Memory reproduction ability), Short-term memory recall (delayed reproduction ability), Attention, concentration, and other (attention, Memory).

Since the frontal lobe, centered around the prefrontal cortex, has been shown to be activated during dual-task activities where two tasks are performed at the same time [15], frontal lobes are considered to be important brain areas trained by these interventions. Indeed, test results using electroencephalogram or near infrared spectroscopy, have shown activation of the frontal lobe when dual-tasks are performed [16,17]. Since functional deterioration due to aging of the prefrontal cortex occurs earlier than the functions supported by other brain regions [18], it is important to design cognitive function training activities that activate the frontal lobe region of the brain including the prefrontal cortex and implement them early in the elderly.

The n-back task is a method for measuring short-term memory ability introduced by Wayne Kirchner in 1958. Since then it has been shown that this method not only a tool for measurements, but also has effects on improving short-term memory capability and has been utilized as a brain training method [19]. Up to now, the improvement of fluid intelligence [20], by increasing the levels of dopamine [21] has been validated, and synergistic effects can be produced with dualtasks.

In addition, from this study, the correlation between salivary $\alpha$-amylase (reflecting stress) and cognitive function was demonstrated. Therefore, it was shown that reduction of stress is indispensable for maintaining and improving cognitive function. Chronic stress induces cell aging [22], which is a cause of physical and mental deterioration called functional human syndrome [23]. Therefore, not only for prevention of dementia, but also for the mental and physical well-being of individuals, stress management in older age are significant. Compared with personal learning training, group-games can be expected to improve mood of affected individuals by enhancing interpersonal communication [24].

Also, based on the correlation between dementia and lifestyle diseases, improvement of dietary habits is indispensable in prevention. However, there are only a few studies that have examined correlation between body composition and cognitive function. In this regard, we believe that the increased self-awareness of body composition and cognitive function by the affected individuals it will lead to more effective selfmanagement. In this study, it was thought that notifying the test results of the correlation between the vascular age and the cognitive function to the study participants and improved the motivation for self-management and helped maintain high participation rates.

Interestingly, the average values of the vascular age as well as the visceral fat levels were higher in the 70s than the age of 80s. These are data likely reflect long-term lifestyle habits and clearly indicate the need for improved dietary habits. This is especially concerning, since people with dyslipidemia and diabetes are increasing year by year [25], therefore, effective preventive measures are urgently needed. Future studies are needed to determine the precise factors that affect cognitive function, in order to refine intervention methods and potentially prevent AD onset.

\section{Conclusion}

Interventions using group-games with a combination of n-back task and dual-task improved cognitive function and reduced stress. It is clear that there is a negative correlation between salivary $\alpha$-amylase that reflects stress and cognitive function; therefore, methods to reduce stress are indispensable to maintain and improve cognitive function. Hence, it is important to promote interventions that act synergistically to improve cognitive function and reduce stress. Also, since negative correlations were found between vascular age and cognitive function, implementation of preventive measures to reduce arteriosclerosis could also help to maintain cognitive function.

\section{References}

1. (2016) World Health Organization: Media center's fact sheets of Dementia.

2. Qiu C, Kivipelto M, von Strauss E (2009) Epidemiology of Alzheimer's disease: occurrence, determinants, and strategies toward intervention. Dialogues Clin Neurosci 11(2): 111-128.

3. Holmes C, Boche D, Wilkinson D, Yadegarfar G, Hopkins V, et al. (2008) Long-term effects of Abeta42 immunization in Alzheimer's disease: follow-up of a randomised, placebo-controlled phase I trial. Lancet 372(9634): 216-223.

4. Alzheimer's Association Research Center (2014) World wide alzheimer's disease neuroimaging initiative. alzheimer's association national office. 


\section{Current Research in Diabetes \& Obesity Journal}

5. Verghese J, Lipton BR, Katz MJ, Hall CB, Derby CA, et al. (2003) Leisure activities and the risk of dementia in the elderly. N Engl J Med 348(25): 2508-2516.

6. Owen AM, McMillan KM, Laird AR, Bullmore E (2005) N-back working memory paradigm: A meta-analysis of normative functional neuroimaging studies. Hum Brain Mapp 25(1): 46-59.

7. Al-Yahya E, Johansen-Berg H, Kischka U, Zarei M, Cockburn J, et al. (2016) Prefrontal cortex activation while walking under dual-task conditions in stroke: a multimodal imaging study. Neurorehabil Neural Repair 30(6): 591-599.

8. Ohsugi H, Ohgi S, Shigemori K, Schneider EB (2013) Differences in dual-task performance and prefrontal cortex activation between younger and older adults. BMC Neurosci 14: 10.

9. Kivipelto M, Ngandu T, Fratiglioni L, Viitanen M, Kåreholt I, et al. (2005) Obesity and vascular risk factors at midlife and the risk of dementia and Alzheimer disease. Arch Neurol 62(10): 1556-1560.

10. Fumura A (2013) Current status and prospect of development of alzheimer's disease treatment based on oxidative stress hypothesis clinical nerve 53: 1043-1045

11. Fredrickson LB, Branigan C (2005) Positive emotions broaden the scope of attention and thought-action repertoires. Cogn Emot 19(3): 313-332.

12. West RL, Bagwell DK, Freudeman AD (2008) Self-efficacy and memory aging: the impact of a memory intervention based on self-efficacy. Neuropsychol Dev Cogn B Aging Neuropsychol Cogn 15(3): 302-329.

13. Yamaguchi M, Kanamori T (2001) Can salivary amylase activity be an indicator of stress estimation? Medical electronics and bioengineering 39: 234-239.

14. Takai N, Yamaguchi M, Aragaki T, Eto K, Uchihashi K, et al. (2004) Effect of physiology stress on the salivary cortisol and amylase levels in healthy young adults. Arch Oral Biol 49(12): 963-968.
15. Seligmann GY, Hausdorff JM, Giladi N (2008) The role of executive function and attention in gait. Mov Disord 23(3): 329-342.

16. Holtzer R, Mahoney JR, Izzetoglu M, Izzetoglu K, Onaral B, et al. (2011) fNIRS study of walking and walking while talking in young and old individuals. J Gerontol A Biol Sci Med Sci 66(8): 879-887.

17. Anguera JA, Boccanfuso J, Rintoul JL, Al Hashimi O, Faraji F, et al. (2013) Video game training enhances cognitive control in older adults. Nature 501(7465): 97-101.

18. Otsuka Y, Osaka N (2005) Working memory in the elderly: Role of prefrontal cortex. Japanese. Psychological Review 48: 518-529.

19. Kirchner WK (1958) Age differences in short-term retention of rapidly changing information. J Exp Psychol 55(4): 352-358.

20. Susanne JM, Studer Luethi B (2010) The relationship between n-back performance and matrix reasoning - implications for training and transfer. Intelligence 38(6): 625-635.

21. Lyubomirsky SL, King L (2005) The benefits of frequent positive affect: Des happiness lead to success? Psychological Bulletin 131: 803-855.

22. Ogawa T, Ikejima NS, Konishi H, Makino T, Sei H, et al. (2009) Chronic stress elicits prolonged activation of alpha-MSH secretion and subsequent degeneration of melanotroph. J Neurochem 109(5): 13891399.

23. Henningsen P, Zipfel S, Herzog W (2007) Management of functional somatic syndromes. Lancet 369(9565): 946-955.

24. Understanding of the elderly with dementia through the reminiscence method : Focusing on caregivers Graduate school of Fukuoka Jogakuin University. Clinical psychology 5: 47-55

25. (2015) Ministry of Health, Labor and Welfare in Japan: 2014 patient survey Overview.

Your next submission with Juniper Publishers will reach you the below assets

- Quality Editorial service

- Swift Peer Review

- Reprints availability

- E-prints Service

- Manuscript Podcast for convenient understanding

- Global attainment for your research

- Manuscript accessibility in different formats

( Pdf, E-pub, Full Text, Audio)

- Unceasing customer service

Track the below URL for one-step submission https://juniperpublishers.com/online-submission.php 